\title{
Denture Hygiene Habits among Elderly Patients Wearing Complete Dentures
}

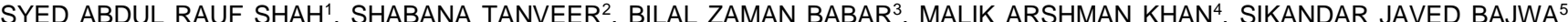
SALVAN GHANI ${ }^{6}$, MARYAM KHURSHID ${ }^{7}$

${ }^{1}$ Professor \& HOD Oral \& Maxillofacial Surgery Bolan Medical College Quetta

${ }^{2}$ Lecturer

${ }^{3}$ Head of Dental Material Department Women Medical \& Dental College Abbottabad

${ }^{4}$ Associate Professor \& Head Department of Oral Biology Abbottabad Medical \& Dental College Abbottabad

${ }^{5}$ Associate Professor Department of Oral Biology Lahore Medical \& Dental College

${ }^{6}$ Assistant professor Department of oral biology women medical \& dental college

${ }^{7}$ Senior Lecturer Department of periodontology

Correspondence to Dr Sikandar Javed Bajwa Email sikandar.bajwa15@gmail.com

\begin{abstract}
Aim: To determine the denture cleaning routine and habits in complete denture wearers according to cleaning frequency, patient age and life of dentures.

Methods: In this cross-sectional study, a self-administered questionnaire was designed to learn about patient's attitudes toward denture cleanliness in the Prosthodontics department. A detailed questionnaire was applied for total 130 patients visiting the Department of Prosthodontics in the Rehmat memorial postgraduate hospital Abbottabad for follow-up care. Data was recorded and analysed by using SPSS version 15.0 for results.

Results: Total 130 participants including 90 males (69.3\%) and 40 females (30.7\%). 48.6\% of participants clean their dentures every day, $32.9 \%$ once a week, and $18.5 \%$ only occasionally. The highest percentage is seen in Group 1 , which is $41.2 \%$. Approximately $77 \%$ of Group 2 participants clean their dentures at least once a week, including both daily and once-a-week denture wearers. 71 individuals had been wearing dentures for $3-5$ years. $41.2 \%$ of them clean their dentures every day, while 58.6 percent clean them twice a week. 6-8 years denture wearers do not clean them on a regular basis. Most patients $42 \%$ use only water, while $30 \%$ use a combination of water and a toothbrush. Around $20 \%$ of participants used soap and water, but only $8 \%$ of denture wearers utilised cleansing tablets in addition to water. There was significant difference among all groups $(P=0.001)$. Conclusion: In this study it has been observed that full denture patients have trouble cleansing their dentures. A lack of regular cleaning practises and decreased use of cleaning solutions is the primary cause of poor denture hygiene among the seniors. Dentists should educate patients regarding optimal denture maintenance and materials used for cleaning verbally and in written form.
\end{abstract}

Keywords: Denture Complete Denture hygiene, cleansing Habits, Denture cleaning solution.

\section{INTRODUCTION}

Recently, there has been increased interest in the oral health of the old age, owing to the expanding global population of the old because of a rise in life expectancy. Old-age dental care has increased in importance since oral tissue changes have been linked to numerous diseases ${ }^{1}$.

Motivation and awareness of prosthetic care are essential to the effectiveness of rehabilitation treatment. Denture fitting surface play vital role along with occlusal relations, age of denture, and cleanliness all have a role in the incidence of oral mucosal ulcers ${ }^{2}$.

Prevention is a critical factor of dental care and includes regular oral hygiene. All Patients, including denture wearers, must keep their edentulous oral cavity clean to avoid lesions ${ }^{3}$. Denture hygiene habits have been found to be inadequate amongst elderly. This may be due to decreasing manual abilities due to advanced age $^{4}$.

Despite several advancements in preventative and curative dentistry, a persistent concern in ageing populations is the high rate of edentulism, which is related to an increasing incidence of periodontal disease and caries. The most frequent therapy for total loss recovery is complete dentures. Rehabilitative treatment works best when patients understand proper prosthesis use and cleanliness ${ }^{5}$.

It is essential for a patient to maintain denture hygiene to avoid oral mucosal infections. One of most vital part is to proper cleansing of food remnants from denture as they can remain hidden between mucosa and denture and can cause bacterial growth $^{6}$. Additionally, these bacteria may spread infection along pulmonary track and GIT. To eliminate this risk, it is critical to clean denture properly and disinfect in solution and clean the denture using brush to avoid damage to oral tissues ${ }^{7}$.

Received on 24-04-2021

Accepted on 03-10-2021
However, it's been observed in this study that full denture patients have trouble cleansing their dentures ${ }^{8,9}$ thus initiatives that promote dental health have been helpful. Most old age patients could not attend dental professional for regular maintenance and management of their dentures, and they do so only when it is very necessary ${ }^{10}$. Therefore, dentists must assist their patients in correctly cleaning their dentures and in finding the right materials to use.

Instructions for washing dentures and mouth after meals should be given. Denture cleaners and brushes should be used to clean the mucosal surfaces of the ridges and the dorsal surface of the tongue daily. Denture wearers, on the other hand, tend to neglect oral hygiene. This might be attributed to deteriorating manual ability because of senior age. Therefore, this crosssectional study was undertaken to explore the oral hygiene practises of denture users of advanced age.

\section{METHODOLOGY}

Inclusion Criteria: Patient got prosthesis from Prosthetics department of Rehmat Memorial Postgraduate Hospital Abbottabad

Patients wearing full or one set of complete dentures.

Patients with an age range starts from 50-70or above years.

Exclusion Criteria:

Patients with any psychological disease:

Patients with TMJ disorders

Patients having other type of prosthesis like implant or overdenture Patients who have been using adhesive pasts, or other products

Data Collection Procedure: Research protocol was explained, and written consent of the patient was taken after. A detailed performa was used to record demographic detail of patient including age, sex, level of education

Data Analysis Procedure: SPSS version 15 was used to evaluate quantitative data. Data was presented using descriptive statistics. 
Chi square analyses were employed to discover relationships. The mean and standard deviation were obtained for age and $p$-value was calculated.

A detailed questionnaire was applied for this study to patients visiting the Department of Prosthodontics in the Rehmat memorial postgraduate hospital Abbottabad for follow-up care. The study aimed to determine the oral hygiene of participants due to denture wearing habits.

The total number of denture patients was 130 . They visited Rehmat Memorial Hospital Prosthodontics Department for followup from 2018 to 2020 . Among 130 patients, $69 \%$ were male and $31 \%$ were female. Three age groups were made, including group 1 is from 50 to 60 years of age, while group 2 is from 60 to 70 years of age and group 3 is above 70 years of age.

Following ethical approval from the Institute, a detailed questionnaire was formed. The questionnaire was then evaluated with a group of ten patients to determine its suitability and effectiveness. The respondents were informed of the survey's aim and given signed consent. The questionnaire included demographic data such as age, gender, and time of wearing, as well as questions on attitudes toward denture care, cleaning frequency, and night-time denture-wearing behaviours.

\section{RESULTS:}

The total sample size was 130 individuals, 31 of whom were in the age group 1,64 of whom were in the age group 2, and 35 of whom were in the age group 3 . Overall, $48.6 \%$ of participants clean their dentures almost daily, $32.9 \%$ once a week, and $18.5 \%$ only occasionally or infrequently (Graph 1 ).

Table 1 demonstrates that individuals in age groups 1 and 2, who are between the ages of 50 and 70 , maintain denture hygiene at least once a week. There was a higher percentage of daily denture cleaning habits in group 1. The highest percentage is seen in Group 1, which is $41.2 \%$. Approximately $77 \%$ of Group 2 participants clean their dentures once a week, including daily and once-a-week denture wearers. Of participants in group 3 , which are mostly $70+$ years old, $58.2 \%$ occasionally clean their dentures $(p=0.001)$. Seventy one individuals had been wearing dentures for 3-5 years, according to denture age. 41.2 percent of them clean their dentures every day, while 58.6 percent clean them twice a week. However, those who have been wearing dentures for 6-8 years do not maintain denture care and clean them on a regular basis. Statistical analysis shows significant $p$-value for old denture wearers.(Table 2).

According to the method of maintaining denture cleanliness, most patients (42 percent) use only water, while $30 \%$ use a combination of water and a toothbrush. Around $20 \%$ of participants used soap and water, but only $8 \%$ of denture wearers utilised cleansing tablets in addition to water (Graph 2).

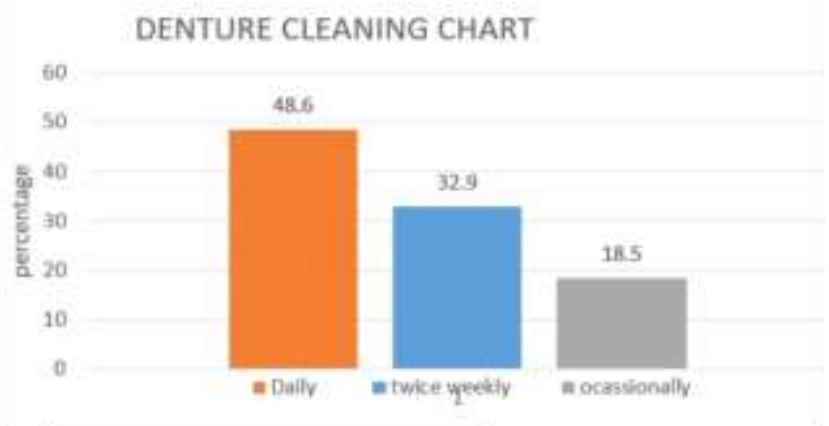

Graph 1. Denture cleaning frequency

Table 1: Age groups and their frequency of denture cleaning per day

\begin{tabular}{|l|l|l|l|l|l|l|l|}
\hline Groups & Age & Total Patients & Once Daily & Twice in a Week & Not Often & Total\% & $\boldsymbol{P}$-Value \\
\hline Group 1 & $50-60$ & 31 & $41.2 \%$ & $23.9 \%$ & $7.5 \%$ & 24 \\
\hline Group 2 & $60-70$ & 64 & $39.6 \%$ & $37.3 \%$ & 0.000 & $34.9 \%$ & 49 \\
\hline Group 3 & $>70$ & 35 & $19.2 \%$ & $38.8 \%$ & 0.000 & $57.6 \%$ & 27 \\
\hline
\end{tabular}

Table 2: Frequency of denture cleansing by age of the dentures
\begin{tabular}{|l|l|l|l|l|l|}
\hline \multirow{2}{*}{ Age of Denture } & Total Patients & Once Daily & Twice in a Week & Not Often & Total \\
\cline { 2 - 7 } & 30 & $26.1 \%$ & $29.3 \%$ & $4.8 \%$ & 23.1 \\
\hline $3-5$ years & 71 & $41.2 \%$ & $58.6 \%$ & $37 \%$ & 0.000 \\
\hline $6-8$ years & 29 & $32.7 \%$ & $13.1 \%$ & $58.2 \%$ & 0.000 \\
\hline
\end{tabular}

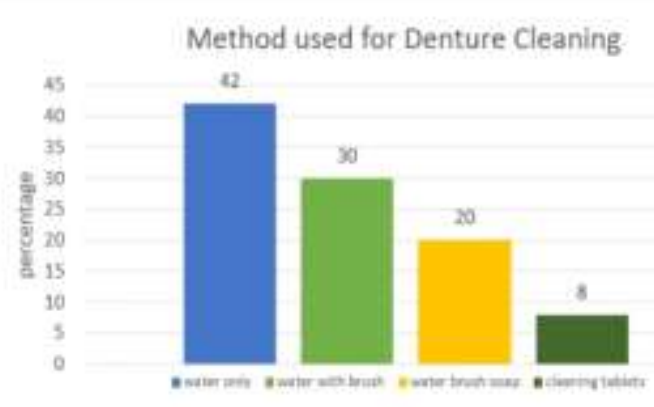

Graph 2. Method used for denture cleansing

\section{DISCUSSION}

In the present study, $42 \%$ of participants use water for cleaning their dentures, and the outcomes were lower than those reported by Apratim et al, but lower than those recorded by Patel et $\mathrm{al}^{2,11}$. It has been shown that people in the 60-70year age group clean their dentures more consistently. Approximately $70 \%$ of the respondents clean their dentures at least once a week when combined with everyday cleaners.

In our research group, the brush with water use rate is \%, a significant increase above that of Patel et $\mathrm{al}^{2}$. Polyzois observed an $86 \%$ prevalence in Australia due to hygiene education being less common in the Indian community. Likewise, Coelho and colleagues (2004) in Brazil reported similar improved findings in their studies. ${ }^{12}$

This may be attributed to the population's lack of information and awareness. Whereas $23.2 \%$ maintain denture hygiene using soap as well along with water and brush, and these findings are comparable to those of the Patel et al study ${ }^{2}$, it was discovered that $8 \%$ keep their dentures in cleaning solutions, which contrasted with Barbosa et al in $2008^{10}$ and Patel et al in 2012. The reason for this might be due to the high cost and negative side effects of bleaching ${ }^{13,14}$.

According to some researchers, use of brush with toothpaste may damage denture surfaces and make it rougher, promoting the build-up of dental plaque and diminishing the shine of denture surfaces ${ }^{15}$. Additionally, brushing without toothpaste is ineffective in removing bacteria that inhabit resinous materials ${ }^{16}$. Cleaning 
dentures is best achieved by brushing and soaking in cleaning solutions ${ }^{17}$.

Around $48.6 \%$ of the study participants answered that they clean their dentures once a day, which was comparable to the findings of Ozcan et $\mathrm{al}^{18}$ who reported that 45.7 percent of the patients clean their dentures once a day. Many studies, however, have found a greater frequency of cleaning, such as Peracini et $\mathrm{al}^{19}$ who found that 73.58 percent of patients washed their dentures 3 times per day, and Pietrokvoski et $\mathrm{al}^{20}$ who found that 96 percent of patients cleaned their dentures 2 times each day.

Cleaning frequency was also shown to be important in relation to denture age. Older dentures, however, were shown to be cleaned less frequently. According to this survey, $58.2 \%$ of denture wearers clean their dentures on a very rare basis in comparison to new denture wearers. Similar findings were reported by Apratim et $\mathrm{al}^{11}$ and Manderson et $\mathrm{al}^{6}$.

Improper denture hygiene results in a variety of oral mucosal diseases linked with removable dentures. This may be a short-term or long-term reaction to oral bacteria, a reaction to the materials in the denture foundation, or mechanical denture damage.

\section{CONCLUSION}

A correlation was established between denture hygiene and gender, education level, the amount of time dentures is worn each day, and whether dentures are immersed overnight. Most dentures are cleaned using toothbrushes. Those with poor denture hygiene are more likely to have dental problems.

Conflict of interest: Nil

\section{REFERENCES}

1. Freitas JB, Gomez RS, De Abreu MH, Ferreira e Ferreira E. Relationship between the use of full dentures and mucosal alterations among elderly Brazilians. Journal of oral rehabilitation. 2008 May;35(5):370-4.

2. Patel IB, Madan G, Patel B, Solanki K, Chavda R. Behaviour and hygiene habits of a sample population of complete denture wearers in Ahmedabad. J Int Oral Health. 2012 May 1;4(2):29.

3. Amjad CM, Azad AA, Ayub MM, Qureshi MA, Javed MU. Denture hygiene habits in complete denture wearers at armed forces institute of dentistry. PAFMJ. 2010 Dec 31;60(4).

4. Kanli A, Demirel F, Sezgin Y. Oral candidosis, denture cleanliness and hygiene habits in an elderly population. Aging Clin Exp Res 2005; 17:502-7

5. Budtz-Jørgensen E. Oral mucosal lesions associated with the wearing of removable dentures. Journal of Oral Pathology \& Medicine. 1981 Apr;10(2):65-80.
6. Manderson RD, Ettinger RL. Dental status of the institutionalized elderly population of Edinburgh. Community dentistry and oral epidemiology. 1975 Jun;3(3):100-7.

7. Sumi $Y$, Miura $H$, Sunakawa $M$, Michiwaki $Y$, Sakagami N. Colonization of denture plaque by respiratory pathogens in dependent elderly. Gerodontology. 2002 Jul;19(1):25-9.

8. Hoad-Reddick G, Grant AA, Griffiths CS. Investigation into the cleanliness of dentures in an elderly population. The Journal of prosthetic dentistry. $1990 \mathrm{Jul}$ 1;64(1):48-52.

9. Kulak-Ozkan Y, Kazazoglu E, Arikan A. Oral hygiene habits, denture cleanliness, presence of yeasts and stomatitis in elderly people. Journal of oral rehabilitation. 2002 Mar;29(3):300-4.

10. Marchini L, Tamashiro E, Nascimento DF, Cunha VP. Self-reported denture hygiene of a sample of edentulous attendees at a university dental clinic and the relationship to the condition of the oral tissues. Gerodontology. 2004 Dec;21(4):226-8.

11. Apratim A, Shah SS, Sinha M, Agrawal M, Chhaparia N, Abubakkar A. Denture hygiene habits among elderly patients wearing complete dentures. The journal of contemporary dental practice. 2013 Nov $1 ; 14(6): 1161$.

12. Coelho CM, Sousa YT, Dare AM. Denture-related oral mucosal lesions in a Brazilian school of dentistry. Journal of oral rehabilitation. 2004 Feb;31(2):135-9.

13. Jagger DC, Harrison A. Denture cleansing--the best approach. British dental journal. 1995 Jun;178(11):413-7.

14. Abelson DC. Denture plaque and denture cleansers: review of the literature. Gerodontics. 1985;1:202-6.

15. Barnabé W, de Mendonça Neto T, Pimenta FC, Pegoraro LF, Scolaro JM. Efficacy of sodium hypochlorite and coconut soap used as disinfecting agents in the reduction of denture stomatitis, Streptococcus mutans and Candida albicans. Journal of oral rehabilitation. 2004 May;31(5):453-9.

16. Schou L, Wight C, Cumming C. Oral hygiene habits, denture plaque, presence of yeasts and stomatitis in institutionalized elderly in Lathian, Scotland. Community dentistry and oral epidemiology. 1987 Apr;15(2):85-9.

17. Dills SS, Olshan AM, Goldner S, Brogdon C. Comparison of the antimicrobial capability of an abrasive paste and chemical-soak denture cleaners. The Journal of prosthetic dentistry. 1988 Oct $1 ; 60(4): 467-70$.

18. Özcan M, Kulak Y, Arikan A, Silahtar E. The attitude of complete denture wearers towards denture adhesives in Istanbul. Journal of oral rehabilitation. 2004 Feb;31(2):131-4.

19. Peracini A, Andrade IM, Paranhos HD, Silva CH, Souza RF. Behaviors and hygiene habits of complete denture wearers. Brazilian dental journal. 2010;21:247-52.

20. Pietrokovski J, Azuelos J, Tau S, Mostavoy R. Oral findings in elderly nursing home residents in selected countries: oral hygiene conditions and plaque accumulation on denture surfaces. The Journal of prosthetic dentistry. $1995 \quad$ Feb 1;73(2):136-41. 